\title{
Sosialisasi Keselamatan Kerja dan Mitigasi Bencana Pada Tempat Pengolahan Akhir Sampah (TPAS) Tamangapa, Kota Makassar
}

\author{
Irwan Ridwan Rahim \\ Departemen Teknik Lingkungan, Fakultas Teknik UNHAS \\ irwanrr@eng.unhas.ac.id
}

\begin{abstract}
Abstrak
Keberadaan sebuah Tempat Pengolahan Akhir (TPA) sampah memang diperlukan oleh suatu daerah karena sampah senantiasa diproduksi oleh penduduk dalam segala aktivitasnya. Selama penduduk terus berkembang maka produksi sampah juga semakin membesar. Sebagian besar sampah perkotaan yang diolah di TPA berasal dari sampah rumah tangga, sampah pasar, sampah perkantoran, dan sampah pusat perbelanjaan. Secara administratif, TPA ini berada di Kelurahan Tamangapa, Kecamatan Mangala, Kota Makassar. Lahan TPA mempunyai luas sekitar 14.3 hektar yang didesain untuk beroperasi sampai tahun 2019. Pesatnya pembangunan membawa dampak pada makin meningkatnya timbulan sampah. Namun peningkatan timbulan sampah ini tidak diiringi dengan pendanaan yang memadai. Keterbatasan dana ini menyebabkan pola penanganan sampah menjadi terganggu. Dimana operasional penanganan sampah yang awalnya didesain sebagai sanitary landfill tidak dilaksanakan secara optimal dan berubah menjadi open dumping. Perubahan operasional penanganan sampah ini membawa dampak pada besarnya peluang resiko bencana.Disamping itu, dari sisi sumber daya manusia, personil yang ditugaskan dalam penanganan sampah perlu ditingkatkan kewaspadaannya terhadap timbulnya kecelakaan kerja dan bencana di TPA.
\end{abstract}

Kata Kunci: Keselamatan Kerja; Mitigasi Bencana; Tempat Pengolahan Akhir Sampah.

\section{Pendahuluan}

Tempat Pemrosesan Akhir (TPA) merupakan tempat dimana sampah mencapai tahap terakhir dalam pengelolaannya sejak mulai timbul di sumber, pengumpulan, pemindahan/ pengangkutan, pengolahan dan pembuangan. TPA merupakan tempat dimana sampah diisolasi secara aman agar tidak menimbulkan gangguan terhadap lingkungan sekitarnya. Karenanya diperlukan penyediaan fasilitas dan perlakuan yang benar agar keamanan tersebut dapat dicapai dengan baik. Berdasarkan data SLHI tahun 2007 tentang kondisi TPA di Indonesia, sebagian besar merupakan tempat penimbunan sampah terbuka (opendumping) sehingga menimbulkan masalah pencemaran pada lingkungan. Data menyatakan bahwa 90\% TPA dioperasikan dengan open dumping dan hanya $9 \%$ yang dioperasikan dengan controlled landfill dan sanitary landfill. Perbaikan kondisi TPA sangat diperlukan dalam pengelolaan sampah pada skala kota. Beberapa permasalahan yang sudah timbul terkait dengan operasional TPA yaitu (Damanhuri, 1995):

1. Pertumbuhan vektor penyakit Sampah merupakan sarang yang sesuai bagi berbagai vektor penyakit. Berbagai jenis rodentisida dan insektisida seperti, tikus, lalat, kecoa, nyamuk, sering dijumpai di lokasi ini.

2. Pencemaran udara Gas metana (CH4) yang dihasilkan dari tumpukan sampah ini, jika konsentrasinya mencapai $5-15 \%$ di udara, maka metana dapat mengakibatkan ledakan.

3. Peningkatan jumlah timbunan sampah, selain sangat mengganggu estetika (pandangan tak sedap), tumpukan sampah ini juga menimbulkan bau tak sedap.

4. Apabila dilakukan pembakaran, asap pembakaran akan sangat mengganggu terutama dalam transportasi dan gangguan kesehatan 
5. Pencemaran leachate. Leachate merupakan air hasil dekomposisi sampah, yang dapat meresap dan mencemari air tanah.

6. Kebisingan Gangguan kebisingan ini lebih disebabkan karena adanya kegiatan operasi kendaraan berat dalam TPA (baik angkutan pengangkut sampah maupun kendaraan yang digunakan meratakan dan atau memadatkan sampah).

7. Dampak sosial Keresahan warga setempat akibat gangguan-gangguan yang disebutkan di atas.

Terkait dengan permasalahan diatas PP No.16/2005 tentang Pengembangan Penyediaan Air Minum mensyaratkan bahwa penanganan sampah yang memadai perlu dilakukan untuk perlindungan air baku air minum. TPA wajib dilengkapi dengan zona penyangga dan metode pembuangan akhirnya dilakukan secara sanitary landfill (kota besar/metropolitan) dan controlled landfill (kota sedang/kecil). Perlu dilakukan pemantauan kualitas hasil pengolahan leachate (efluen) secara berkala. Regulasi berdasarkan UU No.18/2008 mengisyaratkan ketentuan penutupan TPA open dumping menjadi sanitary landfill dalam waktu 5 (lima) tahun, sehingga diperlukan berbagai upaya untuk melakukan revitalisasi TPA.

Keberadaan sebuah Tempat Pengolahan Akhir (TPA) sampah memang diperlukan oleh suatu daerah karena sampah senantiasa diproduksi oleh penduduk dalam segala aktivitasnya (Ardedah and S, 2016). Selama penduduk terus berkembang maka produksi sampah juga semakin membesar(Diharto, 2009). Sistem pengolahan sampah di Kota Makassar saat ini dilayani oleh armada sampah yang pengelolaannya berada dibawah naungan masing-masing kecamatan. Sebagian besar sampah perkotaan yang diolah di TPA berasal dari sampah rumah tangga, sampah pasar, sampah perkantoran, dan sampah pusat perbelanjaan. Secara administratif, TPA ini berada di Kelurahan Tamangapa, Kecamatan Mangala, Kota Makassar. Lahan TPA mempunyai luas sekitar 14.3 hektar yang didesain untuk beroperasi sampai tahun 2019. Karena letaknya dekat dengan daerah perumahan, maka penduduk setempat sering mengeluh terkait dengan bau tak sedap yang berasal dari TPA, terutama pada saat musim hujan (Joyce, 2003). Dari hasil kunjungan lapangan dan wawancara dengan pejabat pemerintah kota, masalah yang paling signifikan yang timbul dari TPA adalah cairan lindi (leachate), bau yang tidak enak, lalat, dan asap dari pembakaran sampah, yang menimbulkan keluhan dari masyarakat setempat. Selain masalah lingkungan, TPA juga mempunyai resiko bencana yang mengancam keselamatan manusia dan properti. Pada musim hujan, resiko bencana longsor mengancam operasi TPA. Sedangkan pada musim kemarau, bencana kebakaran sering terjadi di TPA yang diakibatkan oleh berbagai sebab (Mahyudin, 2017).

Bencana longsor sampah di TPA di Indonesia sudah terjadi beberapa kali, bahkan ada yang membawa korban jiwa. Beberapa di antaranya adalah pada 17 Maret 2010, TPA Sampah Galuga, Kab. Bogor longsor dan mengakibatkan empat korban jiwa. Longsornya TPA Panga, Kab. Toraja Utara yang merusak sawah warga pada 28 April 2011. Longsornya tumpukan sampah di TPA Sanggrahan, Kab. Temanggung untuk ketiga kalinya pada 23 November 2011. 


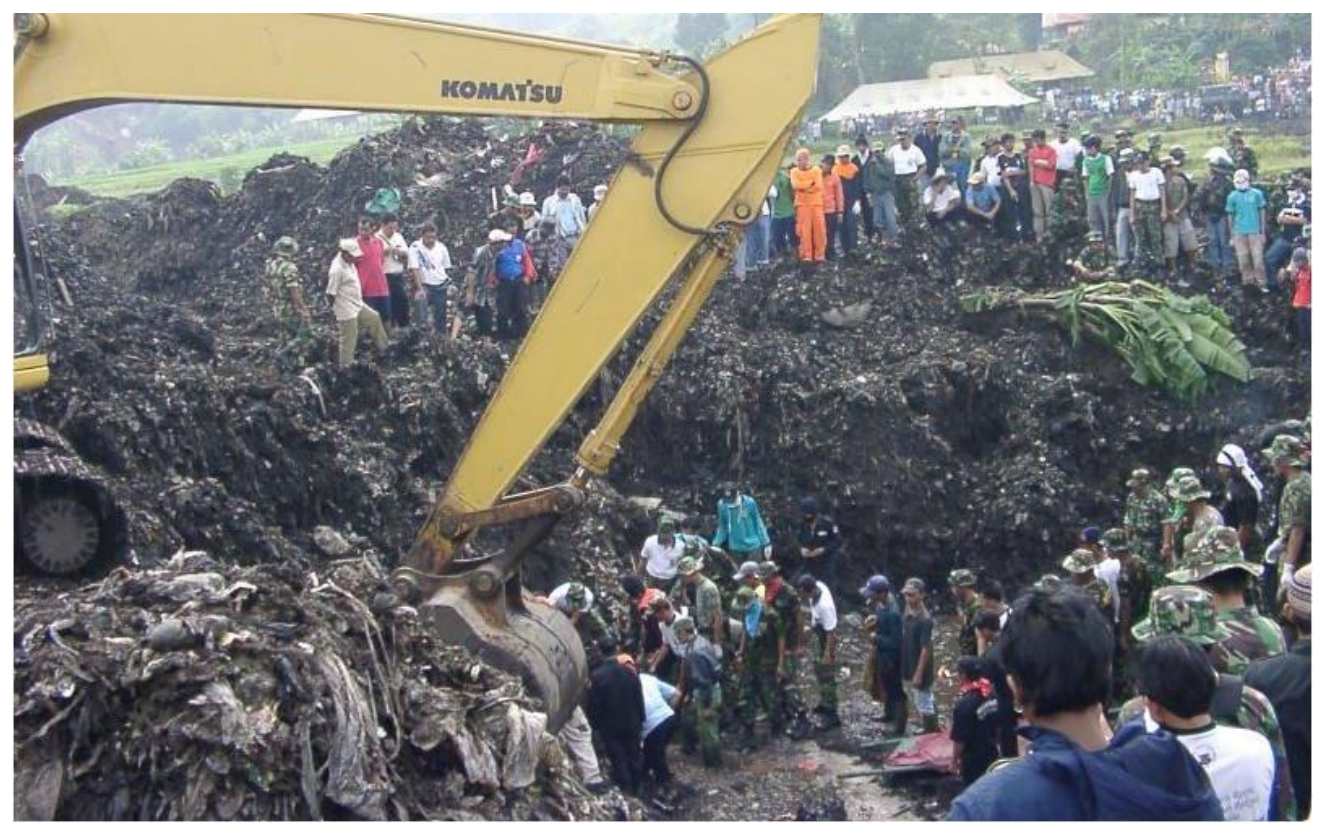

Gambar 1. Evakuasi Korban Bencana Longsor di TPA Leuwigajah, Bandung

Dari sekian banyak peritiwa longsor di TPA, yang paling memprihatikan adalah longsornya TPA Leuwigajah yang menewaskan 156 warga pada 21 Pebruari 2005. Ini menjadi catatan sejarah buruk bagi masyarakat Kota Bandung. Hujan deras yang mengguyur selama 3 hari, menyebabkan longsornya sampah 2,7 juta $\mathrm{m}^{3}$ menutupi wilayah permukiman.

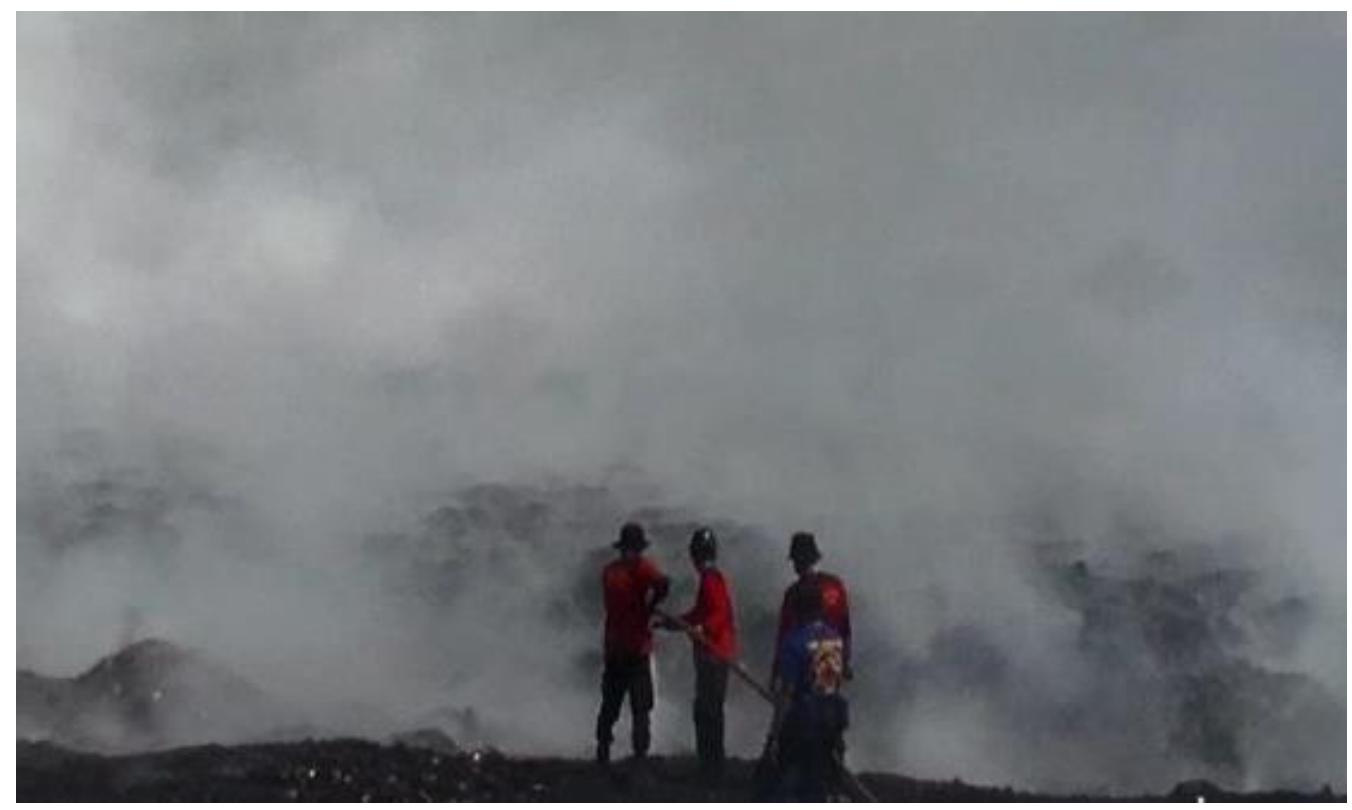

Gambar 2. Suasana Kebakaran di TPA Tamangapa, Makassar

TPA Tamangapa yang mengampung sampah di Kota Makassar pernah mengalami kebakaran, yakni pada tanggal 29 Juni 2009 dan 3 Oktober 2014. Kebakaran TPA juga terjadi di daerah lain seperti pada TPA Banyuurip di Kota Magelang mengalami kebakaran pada 2 September 2015. Kemudian di bulan yang sama disusul oleh kebakaran di TPA Bantar Gebang, Kota Bekasi. pada 
tanggal 11 September 2015. Di bulan berikutnya terjadi beberapa kebakaran seperti pada tanggal 3 Oktober 2015 di TPA Rawa Kucing, Kota Tangerang. Kemudian beberapa hari berikutnya bencana api melahap TPA Jatibarang, Kota Semarang, 9 Oktober 2015. Disusul dengan kebakaran pada tanggal 21 Oktober 2015 di TPA Degayu, Kota Pekalongan. Dampak utama dari kebakaran TPA adalah asap sangat dirasakan warga sekitar yang menyebabkan mata perih dan aromanya mengganggu pernapasan. Selain itu api yang menyebar juga mengancam pemukiman warga (Mizwar, 2012).

\section{Masalah}

Pesatnya pembangunan membawa dampak pada makin meningkatnya timbulan sampah. Namun peningkatan timbulan sampah ini tidak diiringi dengan pendanaan yang memadai (Saleh and Purnomo, 2014). Data dari pemerintah kota menyatakan bahwa alokasi pendanaan persampahan dari pemerintah tergolong rendah yaitu dibawah 5\% dari APBD. Keterbatasan dana ini menyebabkan pola penanganan sampah menjadi terganggu. Dimana operasional penanganan sampah yang awalnya didesain sebagai sanitary landfill tidak dilaksanakan secara optimal dan berubah menjadi open dumping. Perubahan operasional penanganan sampah ini membawa dampak pada besarnya peluang resiko bencana. Disamping itu, dari sisi sumber daya manusia, personil yang ditugaskan dalam penanganan sampah perlu ditingkatkan kewaspadaannya terhadap timbulnya kecelakaan kerja dan bencana di TPA.

Berdasarkan uraian permasalahan mendasar tersebut, maka dirumuskan pokok-pokok permasalahan dalam kegiatan ini sebagai berikut:

1. Bagaimana meningkatkan kewaspadaan pekerja di sekitar TPA terhadap bencana

2. Bagaimana tindakan yang diperlukan untuk mencegah kecelakaan kerja dan bencana di TPA.

\section{Solusi dan Target Luaran}

Untuk menunjang keselamatan operasi di TPA yang selaras dengan rumusan peramasalahan tersebut diatas, maka kegiatan ini akan menawarkan solusi sebagai berikut:

1. Meningkatkan kewaspadaan gugus kerja di TPA terhadap bencana. Hal ini dicapai melalui metode sosialisasi dan penyuluhan kepada grup pekerja yang ditugaskan tentang besarnya peluang bencana yang bias terjadi di lokasi timbulan sampah.

2. Menyusun program kerja untuk pencegahan kecelakaan serta pencegahan bencana longsor dan kebakaran. Hal ini dicapai dengan menyusun prosedur operasi melalui Analisa Keselamatan Kerja (Job Safety Analysis), membuat dan menempatkan tanda-tanda peringatan (signage) di sekitar lokasi TPA.

Manfaat yang dapat diperoleh dari kegiatan pengabdian masyarakat ini adalah sebagai berikut:

1. Meningkatkan kondisi aman dalam operasional pengolahan sampah di TPA.

2. Dengan peningkatan kondisi aman dari bencana, maka penduduk sekitar dapat terhindar dari paparan akibat bencana kebakaran atau longsoran sampah.

\section{Metode Pelaksanaan}

Metode pelaksanaan kegiatan ini secara garis besar terbagi atas 3 bagian, yaitu: tahap persiapan, tahap penyusunan program penanganan bencana dan tahap pelaksanaan kegiatan sosialisasi dan 
desiminasi untuk mewujudkan solusi yang ditawarkan dilaksanakan secara bersama anggota tim pengusul dengan mitra dan dijabarkan sebagai berikut:

A. Tahap Persiapan, terdiri dari beberapa kegiatan:

1.Pembentukan tim yang dilanjutkan dengan rapat untuk menentukan tema, lokasi dan mitra kerjasama.

2.Koordinasi dengan pihak mitra untuk mendiskusikan permasalahan yang utama yang dihadapi dan solusi yang ditawarkan untuk menyelesaikan permasalahan tersebut serta memilih pendekatan untuk merealisasikan solusi yang telah disepakati.

3.Rapat persiapan tim untuk membuat usulan/proposal pengabdian masyarakat.

B. Tahap penyusunan program penanganan bencana, terdiri dari beberapa kegiatan:

1.Kegiatan observasi lapangan dan survei topografi.

2.Kegiatan pemutakhiran chart resiko longsor.

3.Kegiatan penyusunan SOP penanganan bencana

4.Kegiatan penempatan signange

C. Tahap Pelaksanaan Kegiatan sosialisasi dan desiminasi, terdiri dari beberapa kegiatan:

1.Penyampaian undangan untuk meminta kesediaan pihak terkait di Pemerintah Kota Makassar untuk berpartisipasi dalam kegiatan sosialisasi dan penyuluhan yang akan dilaksanakan.

2.Menyiapkan tempat pertemuan yang dilengkapi dengan fasilitas yang cukup untuk menampung peserta yang hadir.

3.Menyiapkan peralatan berupa LCD dan wireless yang akan digunakan dalam pelaksanakan kegiatan.

4.Menyiapkan bahan dan peralatan sederhana sebagai alat bantu pengelolaan limbah padat medis.

5.Pelaksanaan kegiatan penyuluhan dilakukan secara bersama-sama anggota tim.

\section{Kesimpulan}

Kunci keberhasilan pelaksanaan kegiatan sangat ditentukan oleh kerjasama antara anggota tim pengusul dengan mitra. Tanpa adanya partisipasi mitra dalam persiapan hingga pelaksanaan kegiataan, niscaya solusi yang akan ditawarkan untuk menyelesaikan permasalahan tidak terlaksana dengan baik.

\section{Daftar Pustaka}

Ardedah, N. R. and S, P. E. (2016). Perencanaan Tempat Pemrosesan Akhir (TPA) Sampah di Kabupaten Sumenep, Teknik Lingkungan.

Diharto. (2009). Studi Pembangunan TPA Buluminung Kabupaten Penajam Paser Utara, Jurnal Teknik Sipil dan Perencanaan, 11(Juli), pp. 191-200.

Joyce, M. (2003). A Study of the Merits and Effectiveness of Alternate Liner Systems at Illinois Landfills.

Mahyudin, R. P. (2017). Kajian Permasalahan Pengelolaan Sampah dan Dampak Lingkungan di TPAS, Jukung Jurnal Teknik Lingkungan, 3(1), pp. 66-74. Available at: http://www.gasb.org/cs/BlobServer?blobkey=id\&blobwhere=1175824062796\&blobheader=a pplication $\% 2$ Fpdf \&blobcol=urldata\&blobtable=MungoBlobs. 
Jurnal Tepat (Teknologi Terapan Untuk Pengabdian Masyarakat), Volume 1, Nomor 1, Tahun 2018

Mizwar, A. (2012). Penentuan Lokasi Tempat Pengolahan Akhir (TPA) Sampah Kota Banjarbaru Menggunakan Sistem Informasi Geografis (SIG), Jurnal EnviroScienteae, 8(1), pp. 16-22.

Saleh, C. and Purnomo, H. (2014). Analisis Efektifitas Instalasi Pengolahan Lindi TPA Supit Urang Semarang, Jurnal Teknik Pengairan, 5(1), pp. 103-109. 